\title{
Seasonal Sap Flow Dynamics \\ in Larix sibirica Trees Growing in the Krasnoyarsk Forest-Steppe
}

\author{
Anna V. Benkova a , Alexey V. Rubtsov ${ }^{a, b}$, \\ Vera E. Benkova*a and Alexander V. Shashkin ${ }^{\text {a,b }}$ \\ ${ }^{a} V . N$. Sukachev Institute of Forest SB RAS \\ FRC "Krasnoyarsk Science Center SB RAS" \\ 50/28 Akademgorogok, Krasnoyarsk, 660036, Russia \\ ${ }^{b}$ Siberian Federal University \\ 79 Svobodny, Krasnoyarsk, 660041, Russia
}

Received 28.09.2016, received in revised form 11.05.2017, accepted 05.06.2017, published online 06.11.2018

Seasonal dynamics of sap flow in the stems of two Siberian larch trees (Larix sibirica Ledeb.) with different radial growth rates were analyzed. The trees grew nearby Pogorelsky Bor research station of Institute of Forest, SB RAS (Krasnoyarsk forest-steppe, $56.36^{\circ} \mathrm{N}, 92.95^{\circ} \mathrm{E}$ ). Intensity of stem sap flow was measured continuously during the vegetation seasons of 2014 and 2015 using the tissue heat balance (THB) method on two individual trees of the same age and height that grew three meters apart and differed in stem diameter (DBH) only. Seasonal dynamics of sap flow intensity of these trees were synchronous $(R=0.77-0.94)$ within the common vegetation period while the absolute diurnal values differed considerably. The eco-physiological BS-model verified by the data of sap flow measurements allowed to calculate daily and seasonal transpiration dynamics. Seasonal dynamics of sap flow intensity per tree and transpiration per day, and vapor pressure deficit (VPD) as well as seasonal precipitation during the vegetation period were all synchronous. Soil moisture, however, did not show clear correlation with these parameters, thus it may be concluded that it is VPD, but not soil moisture that is the main factor responsible for sap flow intensity in the observed vegetation conditions. The data obtained from the seasons of 2014 and 2015 suggest that continuous automatic measurements of sap flow intensity allow to study phenocycles in trees with various growth rates as well as to determine very precisely the start and the end of their vegetation season.

Keywords: sap flow, transpiration, crown conductivity, weather conditions, BS-model.

Citation: Benkova A.V., Rubtsov A.V., Benkova V.E., Shashkin A.V. Seasonal sap flow dynamics in Larix sibirica trees growing in the Krasnoyarsk forest-steppe. J. Sib. Fed. Univ. Biol., 2019, 12(1), 32-47. DOI: 10.17516/1997-1389-0071.

(C) Siberian Federal University. All rights reserved

This work is licensed under a Creative Commons Attribution-NonCommercial 4.0 International License (CC BY-NC 4.0).

* Corresponding author E-mail address: benkova@yandex.ru 


\title{
Сезонная динамика сокодвижения
}

\section{у деревьев Larix sibirica в Красноярской лесостепи}

\author{
А.В. Бенькова ${ }^{\mathrm{a}}$, А.В. Рубцов ${ }^{\mathrm{a}, \boldsymbol{\sigma}}$, \\ В.Е. Бенькова ${ }^{a}$, А.В. Шашкин ${ }^{\text {a, }}$ \\ ${ }^{a}$ Институт леса им. В.Н. Сукачева \\ ФИЦ «Красноярский научный центр СО РАН» \\ Россия, 660036, Красноярск, Академгородок, 50/28 \\ ${ }^{6}$ Сибирский федеральный университет \\ Россия, 660041, Красноярск, пр. Свободный, 79
}

Проведен анализ сезонной динамики сокодвижения от корней к кроне у деревьев лиственниць сибирской (Larix sibirica Ledeb.), различающихся по скорости радиального роста, произрастающих на территории опорно-экспедиционного пункта ИЛ СО РАН (ОЭП) «Погорельский бор» (Красноярская лесостепь, $56.36^{\circ}$ с.и., $92.95^{\circ}$ в.д.). Непрерывные измерения интенсивности стволового сокодвижения в вегетационные сезоны 2014 и 2015 г2. энергобалансовым (ТНВ) методом проведены на двух одновозрастных деревьях, произрастающих на расстоянии 3 м друг от друга, примерно одинаковой высоты, но разного диаметра. Показано, что сезонная динамика интенсивности сокодвижения у деревьев в общем для них временном интервале в пределах сезона роста характеризуется высокой синхронностью $(R=0.77-0.94)$ при значительной разнице абсолютных значений. С применением эколого-физиологической $B S$ модели, верифииированной по динамике сокодвижения, была рассчитана суточная и сезонная динамика транспирации. Количество транспортируемой воды в день, приходящееся на дерево, транспираџия в день, приходящаяся на единииу листовой поверхности, дефиџит влажности воздуха (VPD) и количество осадков в течение сезона роста меняются синхронно, в то же время связь перечисленных показателей с влажностью почвы выражена не столь определенно. Предполагается, что влажность почвы - не определяющий динамику сокодвижения в стволах исследуемых деревьев в означенном месте произрастания фактор, и этим фактором является VPD. На примере двух сезонов вегетации 2014 и 2015 гг. показано, что непрерывные синхронные автоматические измерения интенсивности сокодвижения позволяют исследовать в древостое феноциклы у деревьев с разными скоростями роста и четко устанавливать точные даты начала и окончания их сезона вегетации.

Ключевые слова: стволовое сокодвижение, транспирация, проводимость кроны, погодные условия, $B S$-модель.

\section{Введение}

В течение последних десятилетий наблюдается беспрецедентное в историческом масштабе усыхание и гибель хвойных древостоев (Allen et al., 2010). Это явление исследо- ватели связывают с глобальным потеплением климата: деревья в современной климатической ситуации часто испытывают водный стресс, который связан с нарушением водного баланса и уменьшением водообеспечения 
органов и тканей ниже пороговых значений (Anderegg et al., 2012, 2015; Rowland et al., 2015 и др.). При превышении адаптивного порога в дереве происходят необратимые изменения (например, изменение цвета кроны или опад хвои после продолжительного стресса, вызванного длительным периодом засухи), которые визуально фиксируются впоследствии, а выявить первоначальный «отклик» дерева на резкий стресс от недостатка доступной влаги сложно. К тому же, по результатам аналитических исследований второй группы экспертов МГЭИК, экосистемы будут реагировать на возможное изменение климата (в том числе и повышение засушливости) различным образом в зависимости от географического положения, структуры экосистем, почвенных и лесорастительных условий, поведения конкретных видов и др. (Bartholy et al., 2013). В этой связи вопросы «локальной адаптации» (в частности, на уровне транспортной функции ксилемы и флоэмы) и выявление возможных механизмов устойчивости древесных растений к засухе вышли в приоритетные (Tyree, Sperry, 1988; McDowell et al., 2008; Гамалей, 2011; Meir et al., 2015; Mencuccini et al., 2015; и др.). Важным элементом при решении означенных вопросов является мониторинг физиологических процессов в дереве, среди которых процесс сокодвижения от корней к кроне (в свете проблемы усыхания) занимает особое место.

Работы по измерению сокодвижения в стволах и ветках древесных растений разных видов начались в 40-х гг. ХХ в., однако широкое распространение в мире эти узкоспециализированные исследования приобрели только в настоящее время в связи с тем, что достигнут высокий уровень автоматизации измерительных систем. Среди современных методов измерения интенсивности сокодвижения в деревьях можно выделить три наи- более используемых: а) энергобалансовый метод (Tissue Heat Balance-метод, далее по тексту ТНВ-метод), основанный на постоянном нагреве водопроводящих тканей (Čermák et al., 2004, 2007; Tatarinov et al., 2005); б) метод Гранье (Granier, 1987), в основу которого положено измерение деформации температурного поля в древесине ствола при сокодвижении; в) метод кратковременного теплового импульса (Marshall, 1958; Swanson, Whitfield, 1981). В России приборно-инструментальные измерения сокодвижения в деревьях в течение длительного времени (одного или нескольких вегетационных сезонов) носят единичный характер (Vygodskaya et al., 1997; Варлагин, 2000; Сазонова и др., 2011; и др.). Исследование процесса сокодвижения в стволах деревьев лиственницы Каяндера и влияния на него многолетней мерзлоты проводилось в 2006 и 2009 гг. на научной станции Института биологических проблем криолитозоны СО РАН «Спасская Падь» (Якутия, Восточная Сибирь) (Iijima et al., 2014). В 2014 г. на базе Института леса Красноярского научного центра СО РАН начаты совместные с Сибирским федеральным университетом работы по внедрению приборно-инструментальных измерений сокодвижения в деревьях в исследовательскую программу.

Цель настоящего исследования - выявление различий в количественных и качественных характеристиках водного режима деревьев лиственницы, различающихся по скорости радиального роста, на базе данных измерений суточной и сезонной интенсивности стволового сокодвижения и результатов моделирования процесса транспирации.

\section{Материалы и методы}

\section{Объекты исследования}

Исследования проводились на базе опорно-экспедиционного пункта Институ- 
та леса им. В.Н. Сукачева (обособленного подразделения ФИЦ КНЦ СО РАН) «Погорельский бор» $\left(56.36^{\circ}\right.$ с.ш., $92.95^{\circ}$ в.д., 427 м над ур. м., Красноярская лесостепь). Климат района резко континентальный со значительными колебаниями температур по годам. Климатограмма, построенная за период 2006-2015 гг. по данным ближайшей (27 км) к месту исследования метеостанции «Сухобузимское» (суточные данные взяты с сайта «Расписание Погоды», http://rp5.co.uk), приведена на рис. 1. Согласно этим данным, среднегодовая температура воздуха $0,16{ }^{\circ} \mathrm{C}$, средняя температура января минус $21,5^{\circ} \mathrm{C}$, июля $18,8{ }^{\circ} \mathrm{C}$. Среднегодовые осадки составляют 431 мм, из них 70 \% выпадает в теплый период года. Средняя продолжительность вегетационного периода 149 дней (Буторина, 1979; Барченков, 2011). Почвы дерновые, сильнооподзоленные, супесчаные. Грунтовые воды залегают на большой глубине, и насаждения используют, в основном, влагу атмосферных осадков (Агроклиматический справочник..., 1961).

Из опытных деревьев, произрастающих в монокультурах лиственницы сибирской (средний диаметр деревьев в популяции 17 см, средняя высота 19 м), для исследования процесса сокодвижения было выбрано два дерева PL1 и PL2 одинакового возраста (48 лет) и приблизительно одинаковой высоты (19.3 и 19.7 м соответственно), но разного диаметра на высоте груди (14.6 и 26.0 см). Расстояние между деревьями было около 3 м (рис. 2). Выбор деревьев разного диаметра в одних и тех же условиях произрастания определялся заметным различием в скорости радиального роста.

\section{Регистрация стволового сокодвижения}

Мы использовали ТНВ-метод, так как площадь нагрева измеряемой части ствола от-

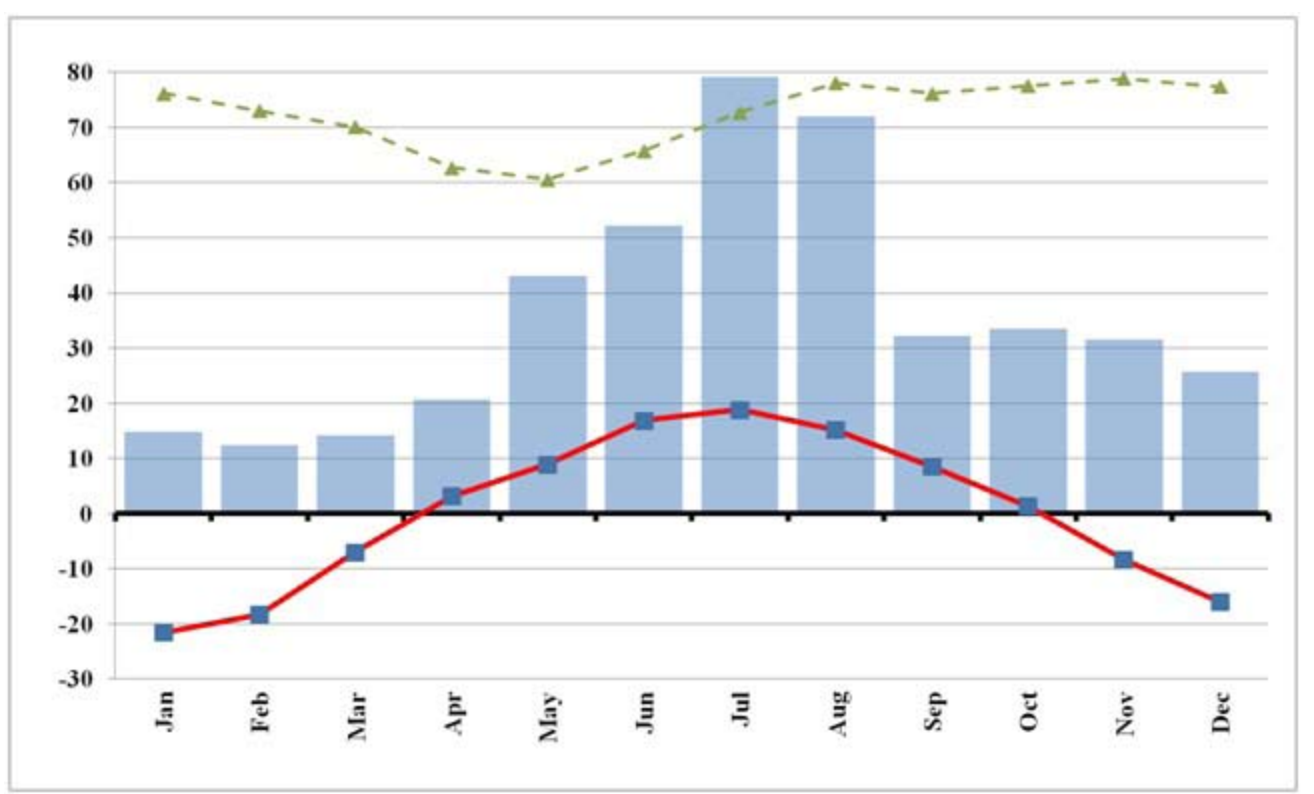

Рис. 1. Климатограмма района исследования по данным метеостанции «Сухобузимо» (2006-2015 гг.): красный цвет - температура воздуха, ${ }^{\circ} \mathrm{C}$; синий - осадки, мм; зеленый - относительная влажность воздуха, \%

Fig. 1. Climatogram of the study region based on meteorological data (2006-2015) from the village of Sukhobusimo: red line - air temperature, ${ }^{\circ} \mathrm{C}$; blue bars - precipitation, mm; green line - relative air humidity, $\%$

$$
-35-
$$




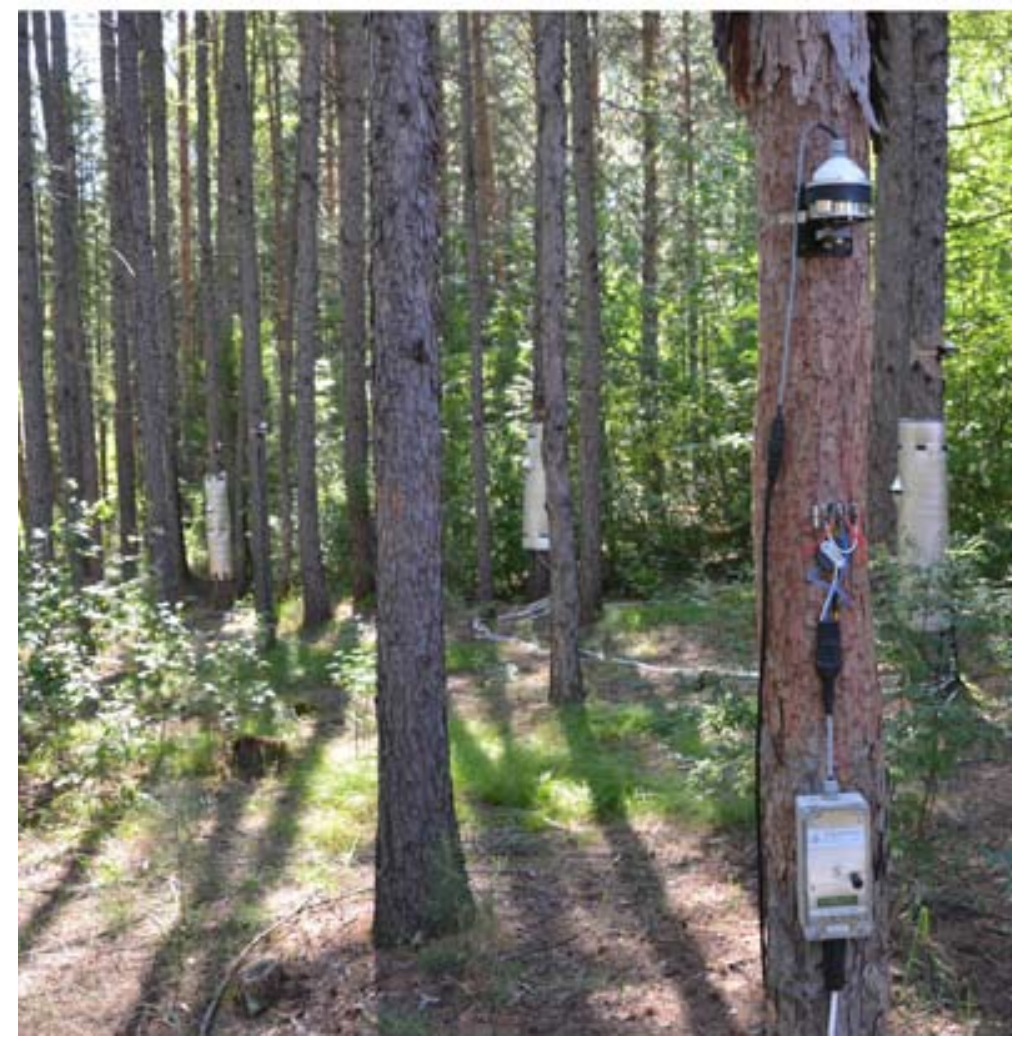

Рис. 2. Опытные деревья лиственницы с установленными модулями регистратора стволового сокодвижения EMS-51A в сочетании с ленточным дендрометром DRL-26: на переднем плане - модуль со снятым изоляционным чехлом на дереве PL2

Fig. 2. Examined larch trees with installed sap flow systems EMS-51A and band dendrometers DRL-26: in the foreground - the sap flow system without the insulation shield on tree PL2

носительно велика, что обеспечивает лучшую стабильность измерений при воздействии косвенных факторов и идентичную их точность (Tatarinov et al., 2005; Renninger, Schafer, 2012) при меньшем энергопотреблении по сравнению с упомянутыми в предыдущем разделе методами.

Используемый нами приборноизмерительный комплекс, изготовленный научно-производственной фирмой «EMS» (Чешская республика, г. Брно), сочетает в себе модули регистрации стволового сокодвижения по методу THB (EMS-51A), датчики температуры и влажности почвы. Это оборудование не требует предварительной параметризации на индивидуальных деревьях; в нем реализованы технологии экономии энергопотребления и автономной работы. Температура каждого электрода измеряется игольчатыми термопарами. Верхние электроды нагревают ткани ствола до температуры, отличающейся от нижнего контрольного электрода на постоянную величину $\Delta T$, задаваемую пользователем $\left(\Delta T=1,2\right.$ или $\left.4{ }^{\circ} \mathrm{C}\right)$. В нашем эксперименте $\Delta T=1{ }^{\circ} \mathrm{C}$. Энергия, необходимая для нагрева электродов и поддержания разности температур $\Delta T$, пропорциональна объемному сокодвижению.

Для расчета интенсивности сокодвижения $Q$ (кг воды в час на 1 см окружности ствола; кг(ч см $\left.)^{-1}\right)$ методом ТНВ используется уравнение: 


$$
Q=\frac{3600 P}{C_{w} \cdot D \cdot \Delta T}-Q^{*}
$$

где $\mathrm{c}_{\mathrm{w}}$ - теплоемкость воды (Дж кг $\left.{ }^{-1}{ }^{\circ} \mathrm{C}^{-1}\right) ; P-$ энегозатраты на нагрев верхних электродов (Дж $\left.\mathrm{c}^{-1}\right) ; D$ - ширина нагрева (см); $Q^{*}-$ коррекция, связанная с теплопотерями в окружающую среду (кг(ч см) ${ }^{-1}$ ) (Čermák et al., 2004).

Теплопотери и соответствующая им коррекция $Q^{*}$ при нагреве ствола зависят от многих факторов, которые сложно учесть, поэтому абсолютную величину $Q^{*}$ принято определять в периоды времени, когда отсутствует стволовое сокодвижение (см. «Инструкция по использованию EMS-51A»). Это наблюдается, как правило, в ночные часы, когда энергозатраты на нагрев минимальны.

Величина Q по формуле (1) рассчитывается на единицу длины окружности ствола, и чтобы рассчитать его на полную окружность ствола (то есть на дерево), используют уравнение

$$
Q_{\text {tree }}=Q(A-2 \pi B)
$$

где $A$ - длина окружности ствола дерева (см); $B$ - суммарная толщина слоев коры и флоэмы дерева (см).

Измерительные модули EMS-51А были установлены на стволах деревьев следующим образом. Три пластинчатых электрода внедрялись в ствол дерева на высоте около 130 см от комля взаимно параллельно и на расстоянии 20 мм друг от друга, а четвертый электрод располагался на 10 см ниже (рис. 2). Электроды были установлены с северной стороны деревьев для минимизации эффекта инсоляции. Непрерывные синхронные измерения перечисленных выше показателей проводились с периодом в 5 мин; данные измерений усреднялись и регистрировались каждые 10 мин с начала апреля до середины октября.
Метеорологические данные - температура $\left(T,{ }^{\circ} \mathrm{C}\right)$ и относительная влажность воздуха ( $R H, \%$, сенсор EMS QT Hi), количество осадков ( $p$, мм, сенсор Pronamic 200), а также температура почвы $\left(T s,{ }^{\circ} \mathrm{C}\right.$, сенсор EMS PT100) на глубинах 10, 20, 40 и 60 см и ее объемная влажность $\left(\mathrm{sm}, \mathrm{M}^{3} / \mathrm{M}^{3}\right.$, сенсор Water Scout SM100) на глубинах 10, 20, 40 см измерялись с временным разрешением 10 мин.

Измерения проводили с начала и до конца вегетационных сезонов 2014 и 2015 гг. К сожалению, в 2014 г. данные по суточным осадкам непосредственно в месте исследования сокодвижения получить не удалось в связи с неисправностью оборудования.

Дефицит влажности воздуха (VPD) рассчитывался стандартным методом с использованием измеренных величин температуры и относительной влажности воздуха (Goff, Gratch, 1946).

Проводимость паров воды кроной $G_{c}$ $\left(\mathrm{M} \mathrm{c}^{-1}\right)$ рассчитывали по известной формуле Монтейна-Унсворта (Monteith, Unsworth, 1990)

$$
G_{c}=K_{g} \frac{Q_{\text {tree }}}{V P D}
$$

где $K_{g}$ - коэффициент, зависящий от температуры воздуха Т $\left({ }^{\circ} \mathrm{C}\right)\left(K_{g}=115.78+0.4236 \mathrm{~T}\right)$ и учитывающий влияние температуры на психрометрическую постоянную, теплоту парообразования, плотность воздуха, а также теплоемкость воздуха при постоянном давлении (Phillips, Oren, 1998).

По данным метеостанции «Сухобузимское», 2014 и 2015 гг. характеризовались приблизительно одинаковыми среднегодовыми температурами и суммарными осадками (420 и 426 мм год $\left.{ }^{-1}\right)$, но в распределении осадков во время сезонов вегетации имелись некоторые различия. Разной была также сезонная динамика дефицита влажности воздуха (данные 
приведены в разделе «Результаты и обсуждение»): дефицит влажности воздуха в 2015 г. в целом был существенно выше.

\section{Расчет транспирацчии}

Расчет транспирации проводился с использованием эколого-физиологической BS-модели радиального роста деревьев в зависимости от погодных условий (Бенькова, Шашкин, 2003), поскольку прямое измерение транспирации для целого дерева в течение сезона вегетации в естественных условиях довольно трудоемко и не всегда возможно. BS-модель базируется на известных биохимических и физиологических принципах и моделях (Fritts, 1976; Farquhar et al., 1980; Running et al., 1987; Leuining, 1991, 1995; Ваганов, Шашкин, 2000; и др.). В ее основу положен расчет скорости фотосинтеза по биохимической модели Факхуpa (Farquhar et al., 1980) с использованием системы уравнений, описывающих устьичную проводимость и скорость диффузии $\mathrm{CO}_{2}$ внутрь листа.

Транспирация воды кроной дерева происходит из-за разности парциальных давлений паров воды в листьях и в окружающем воздухе и по сути своей представляет диффузию паров воды из внутреннего пространства листа в окружающий воздух, которая контролируется устьицами. Транспирация, приходящаяся на единицу листовой поверхности $E$ (кг $\mathrm{M}^{-2}$ сут $\left.^{-1}\right)$, описывается уравнением

$$
E=k g V P D
$$

где $V P D$ - дефицит влажности воздуха (Па); $g$ - устьичная проводимость (м с $\left.{ }^{-1}\right) ; k$ - переводной коэффициент давления паров воды в воздухе в их концентрацию.

В модели предполагается, что транспирация $E$ не может превышать скорость по- глощения воды корневой системой $W$, то есть выполняется соотношение $E \leq W$. Скорость поглощения воды корнями $W$, приходящаяся на единицу поверхности почвы, в модели зависит от влажности почвы $s m$ и от поглотительной способности корневой системы $K$ (кг $\mathrm{M}^{-2}$ сут $\left.^{-1}\right)$ :

$$
W=f(s m) K
$$

где $f(\mathrm{sm})$ - нормализованная безразмерная функция, имеющая кусочно-линейную (трапециевидную) форму (Ваганов, Шашкин, 2000).

Устьичная проводимость $g$ рассчитывается по модели Болла (Ball et al., 1987):

$$
g=g_{0}+g_{1} A h /\left(C_{a}-\Gamma\right)
$$

где $g_{0}$ и $g_{l}-$ константы; $A$ - скорость ассимиляции $\mathrm{CO}_{2}$ (моль $\left.\mathrm{M}^{-2} \mathrm{c}^{-1}\right) ; C_{a}-$ концентрация $\mathrm{CO}_{2}$ в воздухе (моль м'-3); $\Gamma$ - компенсационная точка в присутствии дыхания; $h$ - относительная влажность воздуха с учетом влияния влажности почвы.

Если рассчитанная по уравнению транспирация $E$ превышает $W$, то в этом случае устьичная проводимость уменьшается и становится равной $g^{*}=g W / E$. Скорость ассимиляции $\mathrm{CO}_{2}$ пересчитывается с учетом значения $g^{*}$, при этом выполняется равенство: $E=W$.

Влажность почвы в BS-модели вычисляется исходя из водного баланса в корнеобитаемом слое $(L)$ :

$$
s m(t+1)=s m(t)+(F(p)-E) / L,
$$

где $s m(t)$ и $s m(t+1)$ - влажность почвы в последовательные моменты времени $t$ и $t+1 ; F(p)-$ доля от общего количества осадков $p$, попадающих в почву. 
Входными переменными в BS-модели являются метеорологические данные (суточные величины минимальной и средней температуры воздуха и суммарные суточные осадки), с использованием которых рассчитываются необходимые для моделирования микроклиматические переменные. Минимальная температура воздуха используется для вычисления температуры точки росы, которая с ней линейно связана (Murray, 1967). Остальные параметры, необходимые для моделирования, взяты с теми же значениями, которые использовались в предыдущих расчетах для лиственницы (Бенькова, Шашкин, 2003). Часть параметров взята из литературных источников, часть - подбиралась в процессе моделирования (Бенькова, Шашкин, 2003).

В настоящей работе все расчеты проводились с временным шагом в одни сутки. Скорости всех процессов рассчитывались на единицу площади поверхности почвы.

\section{Результаты и обсуждение}

Рассчитанное по результатам измерений суммарное количество транспортируемой воды за сутки $Q_{\text {tree }}$, проходящее через ствол деревьев PL1 и PL2, характеризуется высокой сезонной вариабельностью (рис. 3) и высокой ее синхронностью в общий для них период сезона роста $(\mathrm{R}=0.77$ и 0.94 в разные годы). Между тем абсолютные значения $Q_{\text {tree }}$ У деревьев существенно различаются: у сравнительно тонкоствольного дерева PL1 (ось ординат на рис. 3 для него расположена справа) максимальные значения $Q_{\text {tree }}$ почти в 8 раз ниже, чем у PL2. Период с конца апреля до середины июня, в пределах которого значения $Q_{\text {tree }}$ имеют возрастающий тренд, соответствует (по натурным наблюдениям) весенне-летнему периоду развития фотосинтетического аппарата у исследуемых лиственниц; при достижении кроной максимального объема показа- тель $Q_{\text {tree }}$ принимает максимальные значения и затем уменьшается, но может оставаться на максимальном уровне в течение некоторого времени в зависимости от индивидуальной реакции деревьев на одинаковые погодные условия. Например, в 2014 г., характеризующемся сравнительно низкими значениями дефицита влажности воздуха (рис. 4в), показатель $Q_{\text {tree }}$ у относительно тонкоствольного дерева PL1 уменьшается уже с начала июля, а у дерева PL2 максимальные значения $Q_{\text {tree }}$ поддерживаются до конца августа (рис. 3). При высоком дефиците влажности воздуха в 2015 г. (рис. 42) у обоих деревьев уменьшение $Q_{\text {tree }}$ происходит с начала июля одновременно. Таким образом, процесс сокодвижения у дерева со сравнительно низкой скоростью радиального роста более «чувствителен» к дефициту влажности воздуха, чем у дерева с высокой скоростью роста. Значения $Q_{\text {tree }}$ постепенно уменьшаются у обоих деревьев до середины сентября. Остановка сокодвижения (при значениях $Q_{\text {tree }}$, близких к 0 ) совпадает по времени с опадом хвои у лиственниц (по натурным наблюдениям).

Судя по данным на рис. 3, даты начала стволового сокодвижения (а также, по натурным наблюдениям, начала распускания почек и формирования фотосинтетического аппарата) у исследуемых деревьев не совпадают. Так, в 2014 г. первые признаки начала сокодвижения у быстро растущего дерева PL2 были зарегистрированы 24 апреля, у медленно растущего PL1 - 17 мая, то есть спустя три недели, а в 2015 г. - 24 апреля у PL2 и 10 мая у PL1, то есть на 2 недели позже. В то же время даты прекращения сокодвижения и окончания сезона вегетации у быстро и медленно растущего дерева различаются не всегда. Так, осенью 2014 г. у дерева PL1 сокодвижение прекратилось на 2 недели раньше (5 и 20 сентября соответственно), 


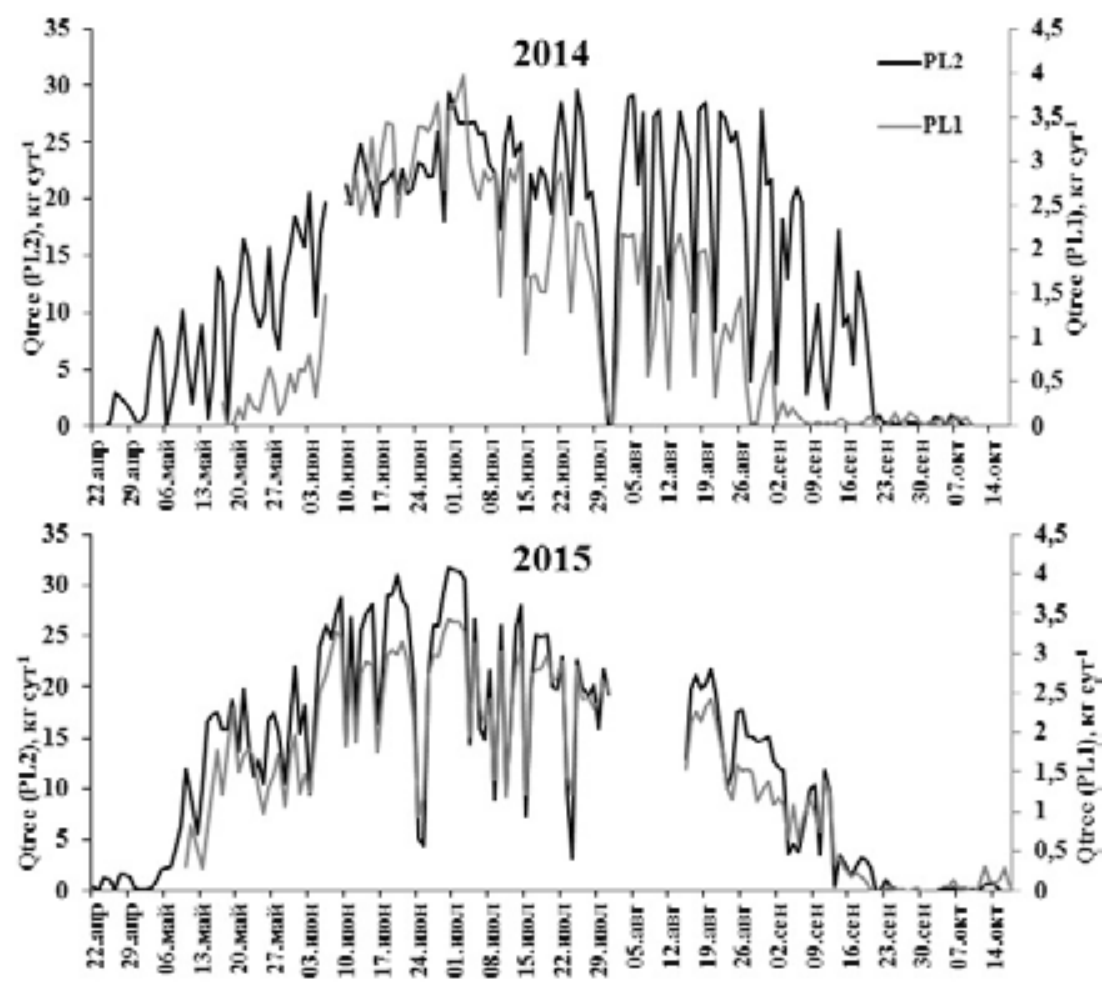

Рис. 3. Количество транспортируемой воды за сутки $Q_{\text {tree }}$ (PL1) и $Q_{\text {tree }}$ (PL2) в стволах деревьев PL1 и PL2 (ось ординат для PL1 изображена справа) в сезоны 2014 и 2015 гг.

Fig. 3. Daily sap flow $Q_{\text {tree }}$ (PL1) and $Q_{\text {tree }}$ (PL2) in the stems of examined trees PL1 and PL2 in the seasons of 2014 and 2015 (the ordinate axis for the PL1 is shown on the right)

а осенью 2015 г. - в одно и то же время, 24 сентября. Различие в датах окончания вегетационного сезона могло быть связано с неодинаковой реакцией деревьев на неблагоприятные погодные события. Так, заморозки в первых числах сентября 2014 г., зарегистрированные метеостанцией в течение трех последовательных ночей, могли оказать сравнительно сильное негативное влияние на тонкоствольное дерево PL1, что привело к прекращению сокодвижения. Осенью 2015 г., не отличавшейся экстремальными погодными событиями, сокодвижение (и, соответственно, сезон вегетации) у деревьев прекратилось одновременно. На примере исследованных деревьев мы заключили, что данные, полученные путем непрерывных сезонных инструментальных измерений ин- тенсивности сокодвижения, позволяют исследовать феноциклы у деревьев древостоя с разными скоростями роста и, что крайне важно, четко устанавливать точные даты начала и окончания их периода вегетации.

Высокая синхронность посуточной изменчивости интенсивности сокодвижения в стволах деревьев PL1 и PL2, заметно ра3личающихся по скорости радиального роста (рис. 3), свидетельствует о том, что этот процесс «управляется» общим внешним фактором. Для его выявления мы провели совместный анализ сезонной динамики сокодвижения $Q_{\text {tree }}$, смоделированной транспирации $E$, дефицита влажности воздуха $V P D$, измеренной влажности почвы $s m$. Различие между сезонами 2014 и 2015 гг. с соответственно низким и высоким VPD отражается 

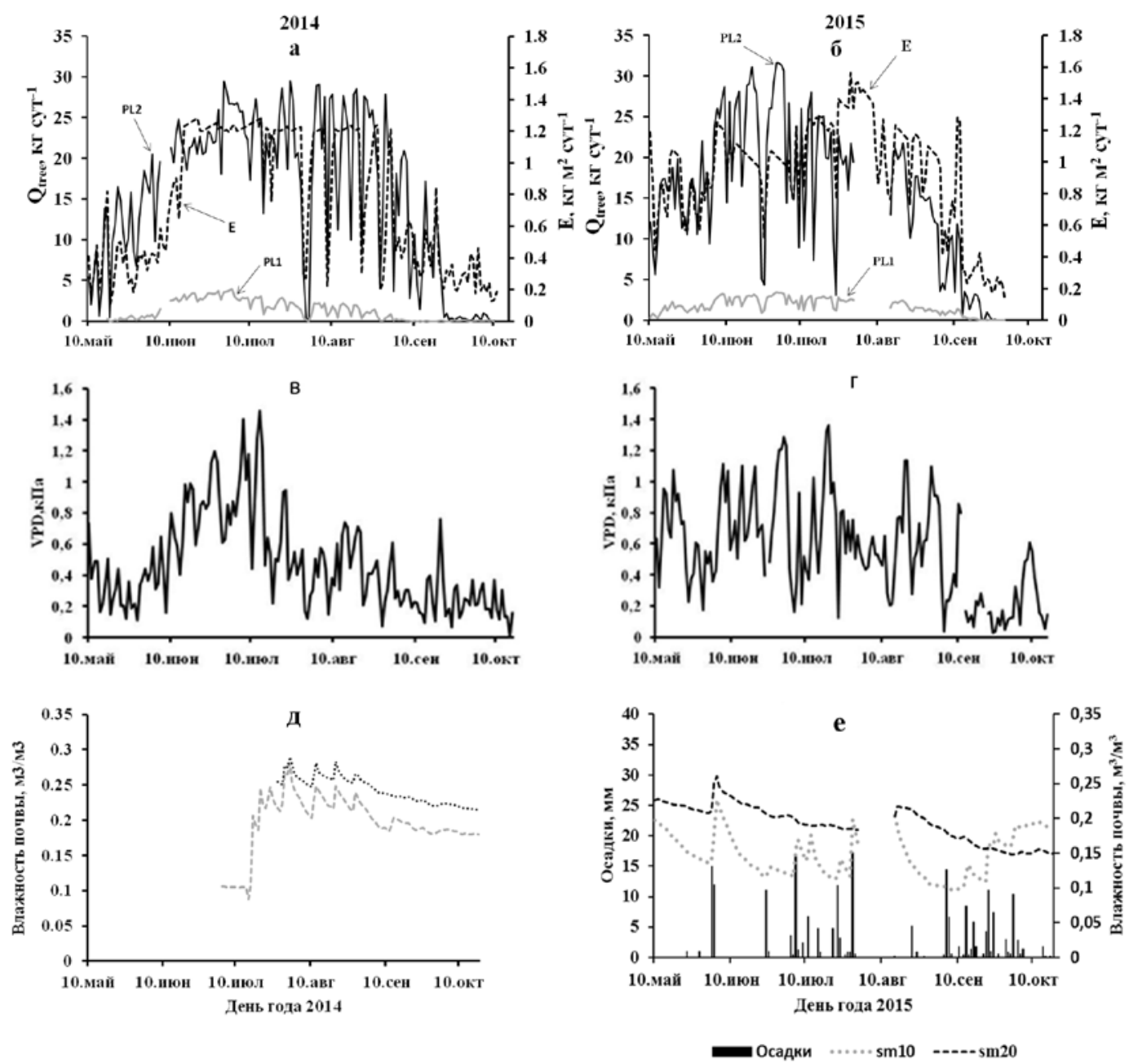

Рис. 4. Сезонная динамика параметров водного режима деревьев PL1 и PL2 (a, б) и микроклиматических характеристик (в-е): $Q_{\text {tree }}$ и $E$ - суточные показатели измеренной интенсивности сокодвижения и рассчитанной транспирации; VPD - дефицит влажности воздуха; sm10 и sm20 - измеренные значения влажности почвы на глубине 10 и 20 см; количество суточных осадков - столбцы (е)

Fig. 4. Seasonal dynamics of water regime parameters for trees PL1 and PL2 (a, б) and microclimatic variables (в-е): $Q_{\text {tree }}$ and $E$ - diurnal measured sap flow intensity and calculated transpiration; VPD - vapor pressure deficit; sm10 and sm20 - soil moisture measured at the depth of 10 and $20 \mathrm{~cm}$, respectively; bars (e) - diurnal precipitation

в абсолютных величинах перечисленных показателей и особенностях их сезонной динамики (рис. 4a-e). Следует подчеркнуть, что абсолютные значения показателей $Q_{\text {tree }}$ и $E$ на рис. $4 a$, $б$ несравнимы, так как имеют разные единицы измерения: $Q_{\text {tree }}\left[\kappa г\right.$ сут $\left.^{-1}\right]$ - это количество воды, проходящее по стволу дерева в сутки, а $E\left[\kappa г \mathrm{M}^{-2}\right.$ сут $\left.^{-1}\right]$ - транспирация единицей листовой поверхности в сутки. Для того чтобы единицы измерения $E$ перевести в единицы измерения $Q_{\text {tree }}$, необходимо оценить полную площадь листовой поверхности кроны. Оценка ее осуществляется, как правило, приближенно, и для этого используются разные способы. Задача данной работы заключалась не в сравнении абсолютных значений $Q_{\text {tree }}$ и $E$, а в анализе степени синхронности их изменчивости в пределах сезона роста, в свя- 
зи с чем различие в единицах измерения не имело значения.

Судя по данным на рис. $4 a, 6$, количество транспортируемой воды за сутки $Q_{\text {tree }}$ и рассчитанная суточная транспирация $E$ варьируют в пределах обоих сезонов (за исключением начала и конца сезона) с довольно высокой синхронностью (коэффициент корреляции $0.80 \pm 0.42)$. В модели не рассматривается развитие кроны в начале сезона роста и старение хвои в конце. Высокая синхронность является показателем того, что уравнение Болла (6), выбранное нами из ряда моделей устьичной проводимости, адекватно описывает сезонные ее изменения на наших объектах исследования за исключением отдельных интервалов времени, когда модель может не работать. Таким образом, BS-модель, которая не учитывает индивидуальных различий деревьев (Бенькова, Шашкин, 2003), позволила получить корректные значения транспирации на единицу листовой поверхности для деревьев лиственницы сибирской, произрастающей в условиях Красноярской лесостепи.

Связь между суточными значениями $Q_{\text {tree }}$ и $E$ для дерева можно описать линейной функцией:

$$
Q_{\text {tree }}=A E+B \text {, }
$$

где $A=0.79 \mathrm{м}^{2}, B=0.32$ кг $\mathrm{M}^{-2}$ сут $^{1}\left(R^{2}=0.67\right)$ для медленно растущего дерева PL1;

$$
A=6.88 \mathrm{M}^{2}, B=3.29 \kappa \mathrm{M}^{-2} \mathrm{cyT}^{-1}\left(R^{2}=0.62\right)
$$
для быстро растущего PL2.

Таким образом, измерив в течение сезона показатели сокодвижения на нескольких деревьях древостоя, различающихся по биометрическим показателям, и рассчитав транспирацию, можно по уравнению (8) устанавливать зависимость коэффициентов $A$ и $B$ от биометрических показателей деревьев. Используя последнюю и дополнительную лесоводственно-таксационную информацию о лиственничнике, можно оценивать транспирацию всего лиственничника для любого последующего или предыдущего сезона, а также другого лиственничника, развивающегося в сходных лесорастительных условиях.

Судя по данным на рис. $4 a-2$, достаточно синхронно в пределах сезонов варьируют $Q_{\text {tree }}$ и VPD. Так, сокодвижение слабой интенсивности наблюдалось у деревьев 24-25 июня и 23-24 июля 2015 г. при низких значениях дефицита влажности воздуха и сопровождалось обильными осадками и увеличением влажности почвы на глубине 10 см. В засушливый период с 29 июня по 2 июля 2015 г. значения $V P D$ и $Q_{\text {tree }}$ были максимально высокими (рис. 4б, г); в это время влажность почвы на глубине 10 см уменьшилась по сравнению с предыдущим и последующим периодами (рис. $4 e$ ).

Таким образом, количество транспортируемой деревом воды в день, транспирация в день, приходящаяся на единицу листовой поверхности, дефицит влажности воздуха, количество осадков (судя по данным за 2015 г., так как измерения количества осадков в сезон 2014 г., к сожалению, не были проведены) изменяются в течение сезона роста в целом согласованно, в то же время связь показателей $Q_{\text {tree }}$, $E$ и $V P D$ с влажностью почвы sm (рис. 4d, e) не наблюдалась в наших условиях. По слабой согласованности внутрисезонных изменений интенсивности сокодвижения и транспирации с влажностью почвы можно заключить, что влажность почвы не является фактором, определяющим динамику сокодвижения в стволах исследуемых деревьев. Дополнительным аргументом в пользу того, что таким фактором выступает влажность воздуха, может служить зависимость интенсивности сокодвижения от дефицита влажности воздуха. Для наглядности представления такого рода 
зависимости мы применили упрощенный подход, который заключался в использовании максимальных в пределах каждых суток значений скорости сокодвижения $Q_{\max }$ и дефицита влажности воздуха $V P D_{\max }$. На наш взгляд, максимальные величины в пределах каждых суток должны соответствовать друг другу, хотя и могут не совпадать по времени в результате запаздывания изменения сокодвижения от изменения транспирации. На рис. $5 a$ приведена зависимость $Q_{\max }=f\left(V P D_{\max }\right)$, построенная за июнь-июльский период сезона (2015 г.), когда фотосинтетический аппарат практически сформирован и процессы развития и «старения» кроны не оказывают заметного влияния на интенсивность сокодвижения. Зависимость представляет собой нелинейную монотонно-возрастающую функцию с на-
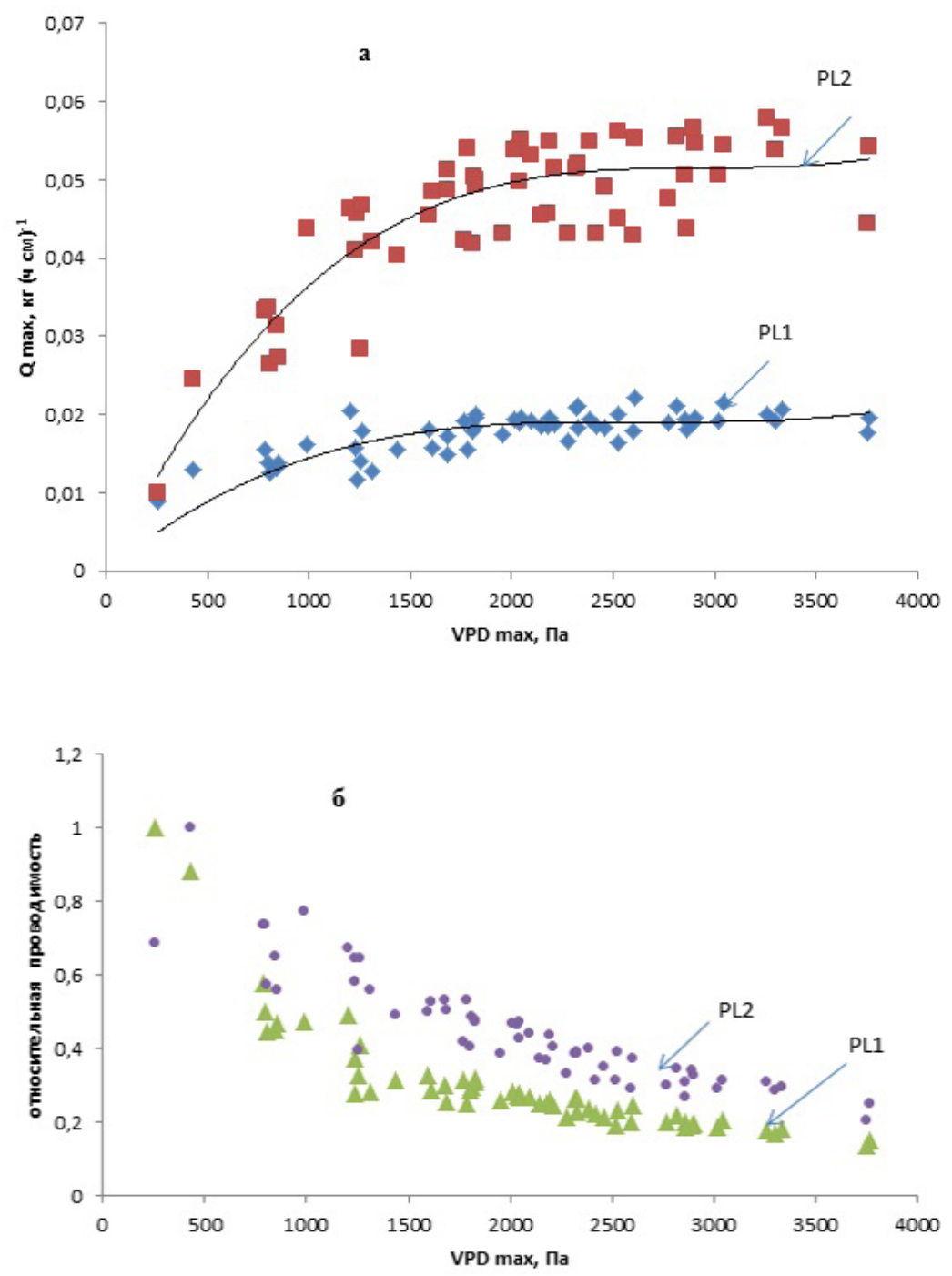

Рис. 5. Изменение максимальной за сутки интенсивности сокодвижения $Q_{\max }$ (а) и относительной максимальной за сутки проводимости кроны (б) у деревьев лиственницы PL1 и PL2 при изменении максимального за сутки дефицита влажности воздуха $V P D_{\max }$ (данные за период июнь-июль 2015 г.)

Fig. 5. Daily maximum sap flow intensity $Q_{\max }$ (a) and relative maximum daily crown conductivity (б) of larch trees PL1 and PL2 vs daily maximum vapor pressure deficit $V P D_{\max }$ (June and July 2015) 
сыщением. Быстрое и приблизительно линейное увеличение $Q_{\max }$ (и транспирации $E$ ) происходит при $V P D_{\max }<1000$ Па, затем рост $Q_{\max }$ замедляется и постепенно достигает предельных значений (при $V P D_{\max }>2000$ Па). Характер зависимости процесса сокодвижения от дефицита влажности воздуха, схожий с таковым на рис. 5, был получен Е.Н. Hogg, P.A. Hurdle (1997) и S. Leuzinger, M.K.-F. Bader (2012) на представителях видов осины (Канада) и ели (Швейцария).

Из рис. $5 a$ следует, что нарушение линейности функции $Q_{\max }=f\left(V P D_{\max }\right) \quad$ при $2000>V P D_{\max }>1000$ Па свидетельствует о проявлении регуляторного влияния устьиц на процесс сокодвижения. Устьица прикрываются, проводимость их уменьшается, в результате чего транспирация снижается, а интенсивность сокодвижения возрастает все медленнее и постепенно стабилизируется на уровне, обусловленном строением водопроводящей системы. В нашем случае предельные значения $Q_{\max }$ при $V P D_{\max }>2000$ Па в интервалах $0.044-0.057$ кг ч $^{-1} \mathrm{~cm}^{-1}$ для дерева PL2 и $0.017-0.023$ кг ч $\mathrm{cm}^{-1}$ для PL1. Таким образом, при высоких значениях дефицита влажности воздуха количество поступающей воды к листьям (в единицу времени) перестает увеличиваться и обеспечивать высокую потенциальную транспирацию. Для защиты растения от излишней потери влаги уменьшается устьичная проводимость. Следовательно, и проводимость кроны в целом уменьшается. Максимальная проводимость кроны деревьев за сутки $\left(G_{\max }\right)$, пропорциональная отношению $Q_{\max } / V P D_{\max }$, рассчитывалась так же, как и $Q_{\max }$, за июнь-июльский период 2015 г. Для перехода к безразмерным (относительным) величинам и для сравнения различающихся деревьев по этому показателю каждое суточное значение $G_{\max }$ нормировалось относительно максимального за весь июнь-июльский пери- од значения $\mathrm{Q}_{\max } / \mathrm{VPD}_{\max }$. Четко выраженное уменьшение относительной максимальной суточной проводимости кроны проявилось у обоих деревьев при максимальном суточном дефиците влажности воздуха выше 1000 Па (рис. 5б); при меньших значениях $\mathrm{VPD}_{\max }$ определенный тренд не выделяется. Нетрудно заметить, что убывание относительной максимальной суточной проводимости при возрастании $\mathrm{VPD}_{\max }$ происходит у быстро и медленно растущего дерева с близкими скоростями (рис. 56 ).

Таким образом, результаты анализа данных на рис. 4 и 5 позволили заключить, что общим для исследованных деревьев, различающихся по скорости радиального роста, внешним фактором, который «управляет» процессом сокодвижения, транспирации и проводимости кроны, является дефицит влажности воздуха.

\section{Заключение}

Комплексный подход, основанный на получении реальных характеристик процесса сокодвижения, расчетных характеристик транспирации и устьичной проводимости, позволил выявить следующее:

- существует высокая синхронность посуточной изменчивости интенсивности сокодвижения у деревьев, заметно различающихся по скорости радиального роста, в общий для них период вегетации;

- общим внешним фактором, который «управляет» сезонным процессом стволового сокодвижения, транспирации и проводимости кроны у деревьев лиственницы с разными биометрическими характеристиками, является дефицит влажности воздуха;

- по сезонным данным измеренной интенсивности сокодвижения и рассчи- 
танной дневной транспирации была верифицирована BS-модель для деревьев лиственницы сибирской, произрастающей в условиях Красноярской лесостепи. Модель не учитывает индивидуальных различий деревьев.
Однако в данной работе модель продемонстрировала высокую синхронность сезонной динамики транспирации на единицу листовой поверхности и сокодвижения у деревьев с разными скоростями радиального роста.

Работа выполнена при финансовой поддержке грантов РФФИ № 14-04-01005, № 14-0400443 u № 17-04-01186.

\section{Список литературы}

Агроклиматический справочник по Красноярскому краю и Тувинской автономной области (1961) Л., Гидрометеоиздат, 288 с. [Agroclimatic handbook for Krasnoyarsk and Tuva Regions (1961) Leningrad, Hydrometeoizdat, 288 p. (in Russian)]

Барченков А.П. (2011) Изменчивость лиственницы в географических культурах в Красноярской лесостепи. Лесное хозяйство, 1: 25-27 [Barchenkov A.P. (2011) Variability of Larix genus in the provenance trial located in Krasnoyarsk forest-steppe. Forest Management [Lesnoye khoziaistvo], 1: 25-27 (in Russian)]

Бенькова А.В., Шашкин А.В. (2003) Фотосинтез сосны и лиственницы и его связь с радиальным приростом. Лесоведение, 5: 38-43 [Benkova A.V., Shashkin A.V. (2003) Photosynthesis of pine and larch related to radial increment. Forestry [Lesovedenie], 5: 38-43 (in Russian)]

Буторина Т.Н. (1979) Биоклиматическое районирование Красноярского края. Новосибирск, Наука, 231 с. [Butorina T.N. (1979) Bioclimatic zoning of Krasnoyarsk territory. Novosibirsk, Nauka, 231 p. (in Russian)]

Ваганов Е.А., Шашкин А.В. (2000) Рост и структура годичных колеи хвойныхх. Новосибирск, Наука, 228 с. [Vaganov E.A., Shashkin A.V. (2000) Tree growth and tree-ring structure in conifers. Novosibirsk, Nauka, 228 p. (in Russian)]

Варлагин А.В. (2000) Транспирация на уровне листа, дерева и сообщества в хвойных лесах: Автореф. дисс. канд. биол. наук. Москва, ИПЭЭ РАН, 37 c. [Varlagin A.V. (2000) Transpiration at leaf, tree, and cenosis levels. Proc. of PhD thesis. Moscow, IPEE RAS, 37 p. (in Russian)]

Гамалей Ю.В. (2011) Криофиты Евразии: происхождение и структурно-функциональная специфика. Ботанический журнал, 96(12): 1521-1546 [Gamalei Yu.V. (2011) Eurasian Cryophytes: origin, and structural and functional particularities. Botany Journal [Botanicheskii Zhurnal], 96(12): 1521-1546 (in Russian)]

Сазонова Т.А., Болондинский В.К., Придача В.Б. (2011) Эколого-физиологическая характеристика сосны обыкновенной. Петрозаводск, Verso, 208 с. [Sazonova T.A., Bolondinskiy V.K., Pridacha V.B. (2011) Eco-physiological description of Scots pine. Petrozavodsk, Verso, 208 p. (in Russian)]

Allen C.D., Macalady A.K., Chenchouni H., Bachelet D., McDowell N., Vennetier M., Kitzberger T., Rigling A., Breshears D.D., Hogg E.H. (Ted), Gonzalez P., Fensham R., Zhang Z., Castro J., Demidova N., Lim J.H., Allard G., Running S.W., Semerci A., Cobb N. (2010) A global overview of drought and heat-induced tree mortality reveals emerging climate change risks for forests. Forest Ecology and Management, 259: 660-684 
Anderegg W.R.L., Berry J.A., Smith D.D., Sperry J.S., Anderegg L.D.L., Field C.B. (2012) The roles of hydraulic and carbon stress in a widespread climate-induced forest die-off. Proceedings of the National Academy of Sciences, USA, 109: 233-237

Anderegg W.R.L., Flint A., Huang C-Y., Flint L., Berry J.A., Davis F.W., Sperry J.S., Field C.B. (2015) Tree mortality predicted from drought-induced vascular damage. Nature Geoscience, 8: 367-371

Ball J.T., Woodrow I.E., Berry J.A. (1987) A model predicting stomatal conductance and its contribution to the control of photosynthesis under different environment conditions. Progress in Photosynthesis Research. Biggins J. (ed.) Dordrecht, Springer, p. 221-224

Bartholy J., Vautard R., Yasunari T. (eds.) (2013) Working group I contribution to the IPCC fifth assessment report climate change 2013: the physical science basis. Chapter 10: detection and attribution of climate change: from global to regional. Cambridge University, UK, $132 \mathrm{p}$.

Čermák J., Kucera J., Bauerle W.L., Phillips N., Hinckley T.M. (2007) Tree water storage and its diurnal dynamics related to sap flow and changes in stem volume in old-growth Douglas-fir trees. Tree Physiology, 27: 181-198

Čermák J., Kučera J., Nadezhdina N. (2004) Sap flow measurements with some thermodynamic methods, flow integration within trees and scaling up from sample trees to entire forest stands. Trees, 18: 529-546

Farquhar G.D., von Caemmerer S., Berry J.A. (1980) A biochemical model of photosynthetic $\mathrm{CO}_{2}$ assimilation in leaves of $\mathrm{C}_{3}$ species. Planta, 149: 78-90

Fritts H.C. (1976) Tree-rings and climate. London, New York, San Francisco, Acad. Press, 576 p.

Goff J.A., Gratch S. (1946) Low-pressure properties of water from -160 to 212 F. Transactions of the American Society of Heating and Ventilating Engineers, 52: 95-122

Granier A. (1987) Evaluation of transpiration in a Douglas-fir stand by means of sap flow measurements. Tree Physiology, 3: 309-320

Hogg E.H., Hurdle P.A. (1997) Sap flow in trembling aspen: implications for stomatal responses to vapor pressure deficit. Tree Physiology, 17: 501-509

Iijima Y., Ohta T., Kotani A., Fedorov A.N., Kodama Y., Maximov T.C. (2014) Sap flow changes in relation to permafrost degradation under increasing precipitation in an eastern Siberian larch forest. Ecohydrology, 7: 177-187

Leuining R. (1991) Modelling stomatal behaviour and photosynthesis of Eucalyptus grandis. Australian Journal of Plant Physiology, 17: 159-175

Leuning R. (1995) A critical appraisal of a combined stomatal-photosynthesis model for $\mathrm{C}_{3}$ plants. Plant, Cell and Environment, 18: 339-355

Leuzinger S., Bader M.K.-F. (2012) Experimental vs. model water use in mature Norway spruce (Picea abies) exposed to elevated CO2. Frontiers in Plant Science, 2: 229

Marshall D.C. (1958) Measurement of sap flow in conifers by heat transport. Plant Physiology, 33: 385-396

McDowell N., Pockman W.T., Allen C.D., Breshears D.D., Cobb N., Kolb T., Plaut J., Sperry J., West A., Williams D.G., Yepez E.A. (2008) Mechanisms of plant survival and mortality during drought: why do some plants survive while others succumb to drought. New Phytologist, 178: 719-739

Meir P., Mencuccini M., Dewar R.C. (2015) Drought-related tree mortality: addressing the gaps in understanding and prediction. New Phytologist, 207: 28-33 
Mencuccini M., Minunno F., Salmon Y., Martinez-Vilalta J., Hölttä T. (2015) Coordination of physiological traits involved in drought-induced mortality of woody plants. New Phytologist, 208: 396-409

Monteith J.L., Unsworth M.H. (1990) Principles of environmental physics. London, Edvard Arnold, $291 \mathrm{p}$.

Murray F.W. (1967) On the computation of saturation vapor pressure. Journal of Applied Meteorology, 6: 203-204

Phillips N., Oren R. (1998) A comparison of daily respirations of canopy conductance based on two conditional time-averaging methods and the dependence of daily conductance on environmental factors. Annals of Forest Science, 55: 217-235

Renninger H.J., Schäfer K.V.R. (2012) Comparison of tissue heat balance- and thermal dissipationderived sap flow measurements in ring-porous oaks and a pine. Frontiers in Plant Science (Functional Plant Ecology), 3: 1-9

Rowland L., da Costa A.C.L., Galbraith D.R., Oliveira R.S., Binks O.J., Oliveira A.A.S., Pullen A.M., Doughty C.E., Metcalfe D.B., Vasconcelos S.S., Ferreira L.V., Malhi Y., Grace J., Mencuccini M., Meir P. (2015) Death from drought in tropical forests is triggered by hydraulics not carbon starvation. Nature, 528: 119-122

Running S.W., Ramakrishna R.N., Hungerford R.D. (1987) Extrapolation of synoptic meteorological data in mountainous terrain and its use for simulating forest evapotranspiration and photosynthesis. Canadian Journal of Forest Research, 17: 472-483

Swanson R.H., Whitfield D.W.A. (1981) A numerical analysis of heat pulse velocity and theory. Journal of Experimental Botany, 32: 221-239

Tatarinov F.A., Kucera J., Cienciala E. (2005) The analysis of physical background of tree sap flow measurement based on thermal methods. Measurement Science and Technology, 16: 1157-1169

Tyree M.T., Sperry J.S. (1988) Do woody plants operate near the point of catastrophic xylem dysfunction caused by dynamic water stress? Plant Physiology, 88: 574-580

Vygodskaya N.N., Milyukova I., Varlagin A., Tatarinov F., Sogachev A., Kobak K.I., Desyatkin R., Bauer G., Hollinger D.Y., Kelliher F.M., Schulze E.-D. (1997) Leaf conductance and $\mathrm{CO}_{2}$ assimilation of Larix gmelinii growing in an eastern Siberian boreal forest. Tree Physiology, 17(10): 607-615 